\title{
The effect of an historical perspective on prospective teachers' beliefs in learning mathematics
}

\author{
Hailu Nigus Weldeana $\cdot$ Solomon Tewolde Abraham
}

Published online: 19 December 2013

(C) The Author(s) 2013. This article is published with open access at Springerlink.com

\begin{abstract}
Many learners hold traditional beliefs about mathematics that can hamper their learning in the discipline. To address this issue, a "history-based" intervention program entailing problem-solving and writing activities that instigate cognitive conflict was implemented. Data sources were pretest and posttest scores of a 12-theme questionnaire designed for this study called "Prospective teachers' beliefs questionnaire about mathematics learning" and written reflections of prospective teachers. The survey of the prospective teachers beliefs related to the nature of mathematics and the way it is learned, taught, and practiced showed a great majority of them failed to hold progressive beliefs. Fortunately, the intervention program has helped the prospective teachers revise and correct their beliefs, thoughts, and understandings. Study of the prospective teachers' written reflections and observations of their oral presentations during whole-class discussions strengthen the results of the quantitative study.
\end{abstract}

Keywords Cognitive conflict · History-based intervention · Problem-solving · Progressive beliefs $\cdot$ Reflective writing $\cdot$ Traditional beliefs

\section{Introduction}

The effects of learners' beliefs related to learning of a subject matter are well-studied. Whereas some beliefs promote learning and performance, others have negative impacts. Various researchers have studied the effects of a variety of beliefs on school subjects and have documented their findings. Mindful of that, mathematics educators have developed

H. N. Weldeana (四)

Mekelle Institute of Technology, PO Box 1632, Mekelle, Ethiopia

e-mail: hwhnweld@gmail.com

S. T. Abraham

North Carolina Central University, Durham, NC 27707, USA 
several instruments and/or courses fostering progressive beliefs and correcting frequently observed traditional beliefs hampering mathematics learning across levels, and with various groups. The works of Beswick (2007), Emenaker (1996), and Hart (2002) are good examples of interventions that helped participants shift their beliefs toward the progressive ones. However, interventions focusing on the history of mathematics are rare, exceptions being the works of Furinghetti (2000), Katz (2000), and Mac an Bhaird (2009).

The present work looks into the effects of "history-based intervention" in challenging traditional beliefs of Ethiopian prospective teachers of middle-grade (5-8) mathematics. For this purpose, the history of mathematics with emphasis of some well-known problems is used as sources of conceptual development. The choice of the "history-based intervention" as exemplified by some well-known problems was made to show that the problems are diverse, context-rich, and broad, and capable of producing cognitive conflict, thereby challenging several traditional beliefs and helping prospective teachers correct those beliefs. Hence, the intervention was carried out to study how it helped participants: (a) understand the historical development of some mathematical ideas, (b) explore the applications of mathematical problems in real life, and (c) assess their beliefs and thoughts on famous problems of mathematics. For this purpose, the participants were exposed to problem-solving and reflective writing activities capable of encouraging cognitive conflict leading to correcting traditional beliefs.

\section{Theoretical framework}

Prospective teachers' beliefs about mathematics

\section{The impacts of beliefs on the learning and teaching of mathematics}

What are beliefs? How are beliefs similar or different with attitudes? Attitudes are consequences of beliefs that range from positive to negative. A number of beliefs may cluster to come up with an attitude. For Kobella (quoted in Sundre et al. 2012, p. 2) “... Beliefs are cognitive basis for attitudes. They provide information for attitudes by linking objects and attributes. A person has many more beliefs than attitudes...." Therefore, teachers' beliefs as factors influencing the understanding of the nature of mathematics, and the teaching and learning of mathematics have long been acknowledged by educators (e.g., Rokeach 1968; Green 1971).

Educators such as Handal (2003), Ernest (1989), and Thompson (1991) have tried to organize frameworks of teachers' mathematical belief systems into smaller subsystems, including of beliefs about the following: (a) the nature of mathematics, (b) the actual context of mathematics teaching and learning, and (c) the ideal context of mathematics teaching and learning. Teachers' beliefs with regard to these subsystems are wide-ranging, including teachers' views on the following: mathematical knowledge; the role of learners and learning; the role of teachers and teaching; and the role of peers, assessment, curriculum, and nature of mathematics activities. Analyses of teachers' views on these subsystems led to the emergence of two major positions in regard to mathematics instruction-progressive or traditional (Handal 2003). Advocates of progressive instruction think that learning is an active construction drawing on prior knowledge as well as a collaborative construction of socially defined knowledge and values through high level of engagement. In this case, teaching needs to be challenging students' thoughts and guiding them toward a complete understanding. Here, teachers are expected to organize the 
learning environment, assess students' thinking, and initiate group activities. The activities need to enhance problem-solving, reflection, exploratory learning, group learning, sufficient discussion, informal and creative thinking, and situated learning (Murphy 1997). On the other hand, proponents of the traditional instruction believe that learning is enhanced as teachers offer accurate information in a sequential and hierarchal manner modeled in a one-way flow strategy. Emphasis is given to pedagogical value of formulas, procedures, algorithms, drills, and isolated concepts in which great attention is given to the product instead of integrating mathematical objects and processes (Handal 2003).

Studies on teachers' beliefs reveal that teachers hold well-articulated beliefs that shape their instructional practice (e.g., Thompson 1992); each teacher holds a particular belief system, comprising a range of beliefs about learners, teachers, teaching, learning, schooling, resources, knowledge, and curriculum (Handal 2003; Leatham 2006); teachers rely on established beliefs to choose pedagogical content and curriculum guidelines (e.g., Clark and Peterson 1986); and teachers reflect their beliefs in their teaching, thus shaping their students' beliefs (e.g., Schoenfeld 1992; Thompson 1992).

Some studies revealed that prospective mathematics teachers hold sets of beliefs that are more traditional than progressive about teaching and learning of mathematics (Hart 2002; Emenaker 1996). Prospective teachers bring, into their education program, views that overvalue memorization of rules, facts, and procedures in learning and teaching mathematics. Examples include viewing that mathematics is a discipline based on facts, rules, and procedures to be memorized, with a prescribed way to arrive at a right answer (Benbow 1993; Nisbert and Warren 2000; Thompson 1992); a mathematical solution is either right or wrong and that mathematics is based on neatness and speed, with one best way to solve a problem (Civil 1990); some people are good at mathematics, while others are not (Frank 1990); and mathematical ability is innate (Foss and Kleinsasser 1996). Traditional beliefs about the nature of mathematics and problem-solving lead to students' failure in solving mathematics problems (Schoenfeld 1992). Whereas progressive beliefs result in successful student learning, traditional beliefs lead to low self-confidence, low self-esteem, low self-perception, and helplessness in learning mathematics, leading to students' lack of motivation and understanding, and underperformance (Boaler 1997; Madden 2008; McLeod 1992; Renga and Dalla 1993; Stevens 2005).

Studies on beliefs in traditional mathematics classrooms revealed that students typically hold various traditional beliefs (e.g., Boaler 1997; Emenaker 1996; Fleener 1996; Hart 2002; Lampert 1990; Schoenfeld 1992). The frameworks on teachers' beliefs mentioned in previous paragraphs about the nature, and the learning and teaching of mathematics guided the present study. However, as the frameworks are more general, twelve specific themes of traditional beliefs are identified for the study. They are as follows:

1. Discovery: Everything important about mathematics is already known by mathematicians (e.g., Hart 2002).

2. Equity: Males are better at mathematics than females (e.g., Hart 2002).

3. Knowing Mathematics: Knowing mathematics is being able to solve problems and getting the right answer quickly (e.g., Lampert 1990; Schoenfeld 1992).

4. Memory: The best way to do well in mathematics is to memorize all facts, algorithms, procedures, and formulas (e.g., Emenaker 1996; Schoenfeld 1992).

5. Nature: Mathematics is a computation using rules, procedures, and algorithms (e.g., Boaler 1997; Davis 1996).

6. Richness: Mathematics and mathematical problems are not rich and varied (e.g., Boaler 1997). 
7. Solution Methods: Mathematics problems can be done correctly in only one way (e.g., Hart 2002).

8. Step: Every mathematics problem should be solved using a step-by-step procedure or using an equation (e.g., Emenaker 1996; Lampert 1990).

9. Time: If a mathematics problem takes a considerable time, it is impossible to solve (e.g., Emenaker 1996).

10. Truth: An answer to a problem is correct if it is ratified by the teacher or by a textbook author (e.g., Fleener 1996; Lampert 1990).

11. Understanding Mathematics: Only the gifted few/geniuses are capable of understanding formulas and equations in mathematics (e.g., Emenaker 1996).

12. Uniqueness: Every mathematics problem has a unique solution (e.g., Emenaker 1996; Schoenfeld 1992).

\section{Changing teachers' beliefs}

The literature dealing with teachers' change of beliefs about the learning and teaching of mathematics is not coherently the same; whereas some research findings confirm change of beliefs is possible (e.g., Bell 1994; Carpenter et al. 1989; Cobb et al.1990; Emenaker 1996; Hart 2002), others reported that it is difficult to change teachers' beliefs (e.g., Collier 1972; Schram and Wilcox 1988; Shirk 1973). A possible reason for disagreement among the researchers as to change of beliefs is that the construct is broad enough and there may be a significant difference in designing an appropriate intervention effective in shifting traditional beliefs to progressive ones. However, after extensive assessment of the literature pro and against on teachers' change of beliefs, several studies (e.g., Beswick 2007; Emenaker 1996; Hart 2002) were found that developed strategies and teaching approaches effective in bringing change of beliefs. According to Thompson (1992), the common characteristics of these methods were as follows:

1. Helping teachers learn by doing and reflecting on their classroom experiences/ practices.

2. Helping teachers develop personal, experientially based reasons and motivations for adjusting classroom practice.

3. Assisting teachers to develop positive views toward the learning and teaching of mathematics through appropriate continuing professional development.

In the late 1970s, Meryerson (cited in Thompson 1992) reported the result of an intervention in a preservice methods course for secondary mathematics teachers aimed to affect change in teachers' conception of knowledge with respect to mathematics and mathematics teaching. In the intervention, Meyerson had designed an intervention that engaged teachers in exercises focusing on seven themes, namely mathematical mistakes, surprise, doubt, reexamination of pedagogical truisms, feelings, individual differences, and problem-solving. Changes in teachers' beliefs were attained as a result of the doubt created during problem-solving that resulted in confusion and controversy. The cognitive conflict teaching approach, which incorporates the four components, of recognition of an anomalous condition, interest, anxiety, and reappraisal of the situation, though shares some similarity with that of Meyerson's, is more explicit and well-defined. This is based on the observable signs that indicate a participant is experiencing cognitive conflict: uncertainty and perplexity when a participant recognizes an anomaly; hesitancy and reappraisal of the situation to try and resolve the conflict; curiosity arousal and a heightened interest in the 
situation; and tension, frustration, and anxiety at finding a question more difficult to solve than expected (Fraser 2007). Specific techniques were also used to manage the cognitive conflict. They are the following: introduction of the relationship and the context of the concept; using appropriate problem triggering cognitive conflict; and creating conducive environment facilitating resolution of the conflict. These reactions were what we used to judge whether a participant was experiencing cognitive conflict as a result of the historybased intervention which aims to challenge traditional beliefs through problem-solving and reflective writing activities.

\section{Cognitive conflict}

Many educational theories developed long ago consider cognitive conflict as a basic tool in teaching and learning of mathematics (e.g., Bruner 1966; Dewey 1933; Piaget 1985; Vygotsky 1978). Cognitive conflict occurs when there is a mismatch or contradiction between the information encoded or how one must act overtly and how the world appears (e.g., Mischel 1971). Resolutions of the contradictions result in learning. Learners change alternative assumptions and attain conceptual change as they are exposed to some sort of cognitive conflict (e.g., Posner et al. 1982). Cognitive conflict also promotes learners' motivation-an important aspect of the affective factor-to resolve the conflict and to learn (Berlyne 1965; Biggs 1990; Festinger 1957; Keller 1984).

Many scholars attempted to investigate how cognitive conflict persuades learning. For Dewey (1933), the origin of thinking is some perplexity, confusion, or doubt that troubles and disturbs one's equilibrium. Piaget (1985) labeled this situation as disequilibrium (cognitive conflict). According to Piaget, when one is aware of cognitive conflict, this identification motivates the individual to attempt to resolve the conflict, in other terms to attain equilibration. Thus, for Vygotsky (1978), when one obtains appropriate assistance from a competent adult or partner, both the individual's power of reflective thinking and cognitive development as a result of cognitive conflict will heighten rapidly. Basically, it answers the question "Given a learner's present state of understanding, what developments can occur if the learner is given appropriate assistance by more capable others when subjected to a situation that instigates cognitive conflict?" Bruner (1966) maintains that when students grow experientially both in terms of reflective thinking skills and cognitive development, they come to depend more and more on language as a tool for representing reality. Further, he argues, symbolic representation, through written and oral language, and allows students to conceptualize processes of reflective thought. As the process of learning is interactive and not linear, experience, imagery, and language support each other in order to boost reflective thinking and cognitive development.

Operational definitions offered for cognitive conflict by researchers are varied and interesting while all have origins from the prominent works of early scholars such as Piaget. For example, Lee et al. (2003, pp. 585-586) defined cognitive conflict as follows: "a perceptual state in which one notice the discrepancy between one's cognitive structure and the environment (external information), or among the different components (e.g., conceptions, beliefs, substructures, and so on) of one's cognitive structure." Likewise, Fraser (2007, p. 27) defined it as "an individual's awareness of contradictory pieces of information affecting a concept in that individual's cognitive structure." Common to these definitions and to others, is that cognitive conflict is being conscious of the inconsistencies that one experiences among the different components of cognitive structure. For the purpose of this research, cognitive conflict refers to an attentiveness of inconsistent information related to one's own conception. 
Cognitive conflict as a teaching tool has been popular in science and mathematics for over three decades. However, there is deviation among researchers on its impact. A literature review by Fraser (2007) revealed that cognitive conflict can be effective, ineffective, or destructive. Many researchers reported its positive impacts (e.g., Adey and Shayer 1993; Bell 1993; Druyan 1997; Hewson and Hewson 1984; Lee and Kwon 2001; Posner et al. 1982). Some scholars, though, found that cognitive conflict failed to lead to desired results (e.g., Niaz 1995; Dreyfus et al. 1990; Elizabeth and Galloway 1996). The outcome of instruction using cognitive conflicts depends on the following: the degree to which affective and cognitive factors are intertwined; the realization of subtypes of cognitive conflict demanding different levels of conflict for its resolution; learners' background and preconceptions; learners' readiness to address inconsistencies in their understanding; learners' diverse characteristics and learning environments; and the components of the cognitive conflict (Fraser 2007; Kwon et al. 2001; Lee and Kwon 2001; Lee et al. 2003; Sinatra and Dole 1998; Stylianides and Stylianides 2008).

It goes without saying that the lack of progressive belief systems about the nature, teaching, and learning of mathematics among prospective mathematics teachers cannot be regarded as purely cognitive behavior. It is also influenced by the affective behaviors the learners hold (Johnson and Johnson 1979). Hence, interventions using cognitive conflict tools that call for learners' cognitive and affective engagement may lead to the development of progressive beliefs that promote learning (e.g., Beswick 2007; Boaler 1997; Goulding 2004; Mac an Bhaird 2009). The potential power of cognitive conflict in transforming traditional beliefs into progressive is addressed explicitly by Morine-Dershimer and Corrigan (quoted in NCCA 2005, p. 204),

... New practices require new beliefs. Changing beliefs involve cognitive stress, discomfort and ambiguity. In changing beliefs, individuals must reconcile or realign other related beliefs to resolve conflicts and contradictions, and come to terms with what actions guided by previous beliefs meant. Such cognitive reorganization is not easily or quickly accomplished.

Changing beliefs is not easily or quickly accomplished as indicated in the above quote, but can be managed by designing an appropriate intervention and employing a suitable strategy. For example, confronting prospective teachers with contradictions that prompt cognitive conflict is a strategy that helps prospective teachers reflect on their current mathematical understandings and thereby recognize the importance of modifying these understandings to resolve the contradictions.

History as a tool of cognitive conflict

Mac an Bhaird (2009) assessed the impact of introducing history of mathematics to students with a weak background in the subject. Students move from a rule-and-procedurefocused practice to basic understanding of the topics. It is argued that history introduces alternative strategies in solving problems, allowing checking of the historical development of mathematical topics and demonstrating that mathematics is a human product (Katz 2000). Learners unaware of the origin, development, and connections of mathematical ideas, concepts, constructs, and principles are susceptible to develop undesirable behavior such as negative attitudes toward the subject, having little understanding of the context or background of mathematics, adhering to bad publicities of mathematics, and encouraging rote learning by heart (Hourigan and O'Donoghue 2007). Hence, promoting students' 
attitudes toward mathematics with the help of history is vital, as it supports their cognitive and affective endeavors in learning of mathematics.

History provides context-rich problems promoting learners thinking in problem-solving and reflective writing (Katz 2000). In this study, prospective teachers were subjected to a teaching approach with conflicting ideas and beliefs so that they were encouraged to reflect on their current understanding of mathematics, confront contradictory beliefs, and recognize the need for modifying these understandings to resolve the contradictions. Historybased intervention in mathematics consistently leads to students' improved understanding and performance (e.g., Furinghetti 2000; Kenschaft 2005; Klyve and Stemkoski 2009; Knoebel et al. 2007; Maor 2007). Thompson (1992), who is one of the foremost writers on teachers' beliefs, supports this position that when teachers with traditional beliefs are subjected to an intervention entailing the history and philosophy of mathematics, they reap progressive beliefs in the end.

As learners are exposed to problems from the history of mathematics that triggers cognitive conflict, they have to deploy problem-solving strategies to resolve the conflict and gain some learning. The Standards and Principles for School Mathematics of the National Council of Teachers of Mathematics (NCTM 2000, p. 52) defined problemsolving as "engaging in a task for which the solution method is not known in advance." Problem-solving is perplexing to most learners and casts light on their existing perception of mathematical ideas and the incongruity created as a result of the puzzling situation. Students' motivation to learn is aroused when they experience absurdity and conflict (Biggs 1990; Keller 1984). According to Schoenfeld (1992), however, to be successful in problem-solving, three aspects of cognition in conjunction with the knowledge of mathematical ideas are essential: They are the following: problem-solving strategies, metacognitive processes, and beliefs and attitudes.

Reflective writing based on problems from the history of mathematics that elicit cognitive conflict is the second important strategy employed in challenging traditional beliefs. For Piaget and Dewey, the mainstay to the learning act is "reflective abstraction." Reflective writing helps learners have focused thoughts, access thoughts for assessment, think at a higher level of complexity, decipher mental images, employ multiple sense organs, and communicate (Haley-James 1982). Idris (2009) maintains that reflective writing helps students identify what they "know" and "do not know" as well as what they "can do" and "cannot do"; in other words, it helps learners develop metacognition-a concept used to refer to conscious monitoring (knowing why and how something is done) and regulation (choosing to do something or making a decision to change thought processes). If these metacognitive goals are attained, students will be able to reflect, organize, model, and represent their thinking meaningfully. Hence, reflective writing-with both affective and cognitive dimensions-is a good strategy for resolving cognitive conflict. It also minimizes destructive effects of cognitive conflict (Hynd 1998; Lee et al. 2003; Sinatra and Dole 1998; Strike and Posner 1992; Tyson et al. 1997).

\section{Research methodology}

Research question

Mathematics education literature shows that prospective mathematics teachers are known to have several traditional beliefs about the nature, learning, and teaching of mathematics. Hence, the goal of this study was to look into the effects of a history-based method of 
teaching in helping prospective teachers shift their beliefs from positions hampering learning to positions facilitating learning in mathematics. The research questions were as follows:

(a) How would the "history-based intervention program" affect prospective teachers' beliefs related to the nature, teaching, and learning of mathematics?

(b) What lessons would be learned from the "history-based intervention program" in challenging traditional beliefs and boosting the development of progressive ones among the participants?

(c) What would be the impact of cognitive conflict in challenging traditional beliefs in transforming them to progressive ones?

Participants and research design

The study was carried out in one middle-grade (5-8) teacher education college in Northern Ethiopia, between September 2008 and February 2009. It began with a survey of 17 themes of beliefs among Year 1, Year 2, and Year 3 prospective mathematics teachers enrolled into $10+3$ diploma program. Once it was known that the three cohorts exhibited similar beliefs of comparable degrees, the Year 2 prospective teachers $(n=63)$ were selected and signed for the study. All of them completed the pretest, and 61 completed the posttest. The participants can be considered as a good representative of prospective teachers in Ethiopia as all prospective teacher education colleges of the country run exactly the same program.

The design of the study was one-group pretest-posttest. It involved the pretest, the intervention, and the posttest. The pretest was carried out to establish participants' beliefs about the nature, learning, and teaching of mathematics before the intervention. The posttest was carried out to establish changes in participants' beliefs about the nature, learning, and teaching of mathematics after the intervention. For the qualitative data obtaining during this study, interpretive qualitative study design, which aimed at understanding how participating prospective teachers make meaning of a situation or phenomenon, was used. The history-based intervention program supported with reflective writing and problem-solving activities to prop up cognitive conflict represents the intervention.

\section{Research instruments}

A 48-items prospective teachers' beliefs questionnaire about mathematics learning and a reflective writing were used in the study as instruments of data collection. The questionnaire consisted of a 12-theme Likert scale in three levels-Agree $=1$; Undecided $=2$; and Disagree = 3 ("Appendix 1"). It was developed by consulting Hart (2002), Emenaker (1996), and Simon and Schifter (1993) with modifications to fit the research purpose. The three-level Likert scale was chosen because of its simplicity to understand compared to a five-level one, and its suitability for the respondents to provide a more accurate response with little room for misunderstanding.

The items in the questionnaire are either favorable (favoring progressive beliefs) or unfavorable (favoring traditional beliefs). Hence, it is assumed that in the case of the favorable items in the questionnaire, a mean value of equal or about equal to 1 signifies that the prevailing beliefs of the participants are progressive. With unfavorable items, a mean value of equal or about equal to 1 signifies that the prevailing beliefs of the participants are traditional. On the other hand, with favorable items in the questionnaire, a mean value of equal or about equal to 3 signifies that the prevailing beliefs of the participants are 
traditional. But with unfavorable items, a mean value of equal or about equal to 3 signifies that the prevailing beliefs of the participants are progressive.

Reflective writing, as a tool of data collection, was used throughout the intervention program, in accompanied with nine problem-solving activities from the history of mathematics ("Appendix 2") and affective activities, except the last two that were used along with the last problem-solving activity ("Appendix 3"). Participants were required to carry out mathematical problem-solving activities and present their reflections in writing and orally in class once a week in $2 \mathrm{~h}$, in the weekends. These activities helped the researchers compile statements and problem solutions that demonstrate the participants' change of traditional beliefs toward progressive ones, and understandings due to their exposure to the history of mathematical ideas, topics, concepts, constructs, and/or principles. Written reflections and problem solutions of the participants were thoroughly read and commented immediately to enrich subsequent activities of the intervention.

\section{Validity and reliability}

The questionnaire was pilot tested several times. Reliability results (Cronbach' alpha) ranging from 0.76 to 0.83 were obtained. Also, an inter-rater agreement between one of the researchers and a statistician trained for some time on prospective teachers' reflective writing was found to be very high. A possible limitation of each instrument is complemented by the other to ensure validity.

\section{"History-based" intervention: the content}

The goal of the history-based intervention was to improve prospective teachers' beliefs about mathematics as well as teaching and learning in the subject. The intervention, a semester long one, involved reflective writing and problem-solving activities to promote progressive beliefs among the participants by exposing them to cognitive conflict.

The intervention, conducted by the first author (teacher-as-researcher), began with revising and updating a prospective mathematics education course to give due emphasis to the historical development of mathematics in general and to the famous problems of mathematics in particular. In this case, the relevant literature was consulted (e.g., Boyer 1991; Eves 1990; Gerland 1987; Masingila et al. 2002; Rosen 2006; Sobel and Maletsky 1988; Wells 1986; World Book 1994). The problem-solving and reflective writing activities required all participants to reflect, invent, imagine, and play with ideas; create and solve problems; theorize, generalize, and describe concepts; express meanings of concepts; and explore, explain, criticize, and justify their reasoning. These would allow the participants to understand how something is accomplished rather than merely being able to perform a task. Representatives of problem-solving and affective activities are given in Table 1. For more details, refer Appendices 2 and 3, respectively.

\section{"History-based" intervention: the implementation}

The study was exploratory aiming at investigating the effect of a history-based intervention, involving problem-solving and reflective writing activities, among prospective teachers of mathematics. Whereas the problem-solving activities (aka Mathematical set) focused on initiating cognitive conflict, the reflective writing activities (aka Affective set) focused on self-reporting of thoughts and ideas used in investigating changes in beliefs 
Table 1 Sample mathematics (problem-solving) and affective questions

\begin{tabular}{|c|c|}
\hline Sample mathematics (problem-solving) set & Sample affective set \\
\hline $\begin{array}{l}\text { Describe the Fibonacci sequence in detail } \\
\text { Use different axiomatic systems to describe the } \\
\text { Fibonacci sequence (recurrence relations, } \\
\text { determinants, and sequence in calculus) } \\
\text { Describe the diverse nature of the Fibonacci } \\
\text { sequence and explore relationships related to the } \\
\text { following } \\
\text { Fibonacci and Nature } \\
\text { Fibonacci and art } \\
\text { Fibonacci and algebra } \\
\text { Fibonacci and geometry }\end{array}$ & $\begin{array}{l}\text { What do you learn from this famous problem and its } \\
\text { nature in this week? } \\
\text { Discuss (in paragraph form) the skills and } \\
\text { knowledge you have developed from this famous } \\
\text { problem and its nature } \\
\text { What was the best thing you gained from this } \\
\text { problem? } \\
\text { Why was it the best gain? } \\
\text { How do you know that it was the best gain? }\end{array}$ \\
\hline
\end{tabular}

among the participants as a result of the cognitive conflict. Moreover, the reflective writing activities are believed to motivate the participants to remain engaged until they reconcile their beliefs against the progressive ones.

Lessons were delivered in such a way that participants realize that mathematics is a human product; and their thoughts and beliefs may be different from what is presented (i.e., create cognitive conflict). The intervention was carried out to (a) provide participants with famous mathematics problems that trigger cognitive conflict, (b) encourage participants to describe and solve the problem, and create or pose new problems, and (c) require participants make written or oral reflections after they resolved the conflict through problem-solving. Activities were supported with unstructured and open-ended questions providing participants the opportunities to reflect on their feelings freely. After the problem-solving activities (i.e., Mathematical set) were delivered or worked out, the reflective writing activities (i.e., Affective set) were followed for each set of the problem-solving activities, except for the last two problems that were left as summary for the last mathematical set. One historically famous problem was delivered each week, with reading assignments. Participants were required to do in-depth interpretations of the contents in a personal way to challenge their own traditional beliefs, as well as to describe, discuss, communicate, and reflect on their old beliefs and new understandings.

Participants worked on problem-solving activities in groups of four or five. Weekly reflective writing assignments were carried individually, and reports were submitted every Friday afternoon. Participants were cautioned to avoid making hasty reflections and advised to take ample time to make conscious reflections. Participants presented their works orally in $5 \mathrm{~min}$ to give room for whole-class discussion, communication, reflection, and negotiation in regard to the topics at hand. Sometimes, discussion and reflection sessions were extended. Extended discussions helped the researchers have sufficient time to offer feedback and relevant comments and rewrite participants' reflections correctly. Pre-presentation reviews of participants' written reflections by both of the researchers helped avoid biases by the teacher-as-researcher favoring reflections of some participants against others.

Data analyses

Pretest and posttest data of the questionnaire were compared using a $t$ test for nonindependent samples. Comparisons were made at a priori fixed value of $p \leq 0.05$. Qualitative data were analyzed using Kitwood's method of analyzing accounts called "tracing a 
theme" (Cohen et al. 2000). First, the two researchers went through the written reflections several times independently. The data collected this way by each of the researchers were shared with the other and inspected for content. Then, each researcher independently developed a category system related to any of the themes identified in the literature a priori, putting all the material in categories he felt right. Then, both researchers worked together to exchange views and negotiate a final category system in relation to the list of the themes. At this level, initial themes established by the individual researcher are then modified and expanded to more specific and detailed themes identified a priori in the literature part. These activities resulted in seven themes. Finally, representative prompts were rewritten to correct/fix language errors and was presented as manifestations of prospective teachers' beliefs after the intervention.

\section{Results and discussion}

Prospective teachers' beliefs about mathematics learning

Comparison of mean pretest and posttest data of the questionnaire revealed shifts in participants' belief systems toward progressive ones. Very strong shifts are observed in beliefs related two themes: time and step both with $p \leq 0.001$ (Table 2). This indicates that prospective teachers evidence a higher degree of disagreement with the favorable statements as well as higher degree of agreement with the unfavorable statements in the pretest and vice versa in the posttest. Data displayed in Table 2 also evidenced that significant shifts had been made in each of the ten themes with $p \leq 0.05$ or $p \leq 0.01$. Thus, the prospective teachers who engaged in problem-solving and reflective writing that instigate cognitive conflict were successful in modifying the traditional beliefs significantly.

Table 2 Mean (SD) of pretest and posttest score of prospective teachers' belief survey

\begin{tabular}{|c|c|c|c|c|c|}
\hline \multirow[t]{2}{*}{ Theme } & \multicolumn{2}{|c|}{ Pretest $(n=63)$} & \multicolumn{2}{|c|}{ Posttest $(n=61)$} & \multirow[t]{2}{*}{$t_{(1,61)}$} \\
\hline & Mean & $\mathrm{SD}$ & Mean & $\mathrm{SD}$ & \\
\hline Discovery & 2.93 & 1.04 & 2.13 & 1.04 & $1.90^{\mathrm{a}}$ \\
\hline Equity & 2.87 & 1.13 & 2.13 & 1.01 & $1.93^{\mathrm{a}}$ \\
\hline Knowing mathematics & 2.76 & 1.00 & 2.12 & 1.25 & $2.62^{\mathrm{b}}$ \\
\hline Memory & 2.67 & 1.02 & 2.14 & 1.12 & $2.16^{\mathrm{b}}$ \\
\hline Nature & 2.61 & 1.12 & 2.01 & 1.20 & $1.98^{\mathrm{a}}$ \\
\hline Richness & 2.69 & 1.15 & 1.87 & 1.16 & $2.11^{\mathrm{a}}$ \\
\hline Solution methods & 2.67 & 0.97 & 1.87 & 1.15 & $1.97^{\mathrm{a}}$ \\
\hline Step & 2.78 & 0.95 & 1.87 & 1.03 & $2.75^{\mathrm{c}}$ \\
\hline Time & 2.89 & 1.11 & 1.92 & 1.11 & $2.57^{\mathrm{c}}$ \\
\hline Truth & 2.49 & 1.05 & 1.89 & 1.10 & $2.03^{\mathrm{a}}$ \\
\hline Understanding mathematics & 2.79 & 0.87 & 1.93 & 1.15 & $2.15^{\mathrm{b}}$ \\
\hline Uniqueness & 2.72 & 1.14 & 1.94 & 1.14 & $2.49^{\mathrm{b}}$ \\
\hline
\end{tabular}


A complete analysis of this quantitative data will be given in integration with the qualitative data in the coming section.

Participants' shift in beliefs

Analyses of prospective teachers' written reflections and oral presentations helped us identify seven themes that demonstrate change of beliefs toward progressive ones. They are (a) time to solve versus nature of the problem - the time required to solve a problem depends on the nature of the problem; (b) diverse applications of problems-mathematical problems are varied and context-rich; (c) multiple solution strategies-there are mathematical problems engaging multiple solution strategies; (d) discovery in mathematicssolving problems of mathematics helps everybody, including ordinary persons, discover new mathematical innovations; (e) gender equity in mathematics-females can perform as well in mathematics as males; (f) memorizations versus understanding-memorization is less important and understanding is superior in mathematics; and ( $\mathrm{g}$ ) knowing versus stepby-step procedure in mathematics - knowing in mathematics is the result of understanding relationships and step-by-step procedures meaningfully.

The intervention was implemented by making sure that participants attend all problemsolving activities triggering cognitive conflict. Hence, the participants were needed to detect (the source of) cognitive conflict and deal with it. The researchers, in turn, could detect that the participants have detected the cognitive conflict and dealing with it, when they observed that the participants exhibited interest, anxiety, and reappraisal of the situation.

Time to solve versus nature of mathematics problems

As we began to explain the historical background in general and to the famous problems included in the intervention course in particular, we learned that the prospective teachers had little or no concept about these problems. As a part of the intervention, participating prospective teachers were required to work on some problems, e.g., Fermat's Last Theorem, Ulam's or the " $3 x+1$ " conjecture, the Four color conjecture, etc. Then, discussion sessions were made with thought-provoking questions such as the following: "What do you learn from this...?" "What skills and knowledge have you developed from...?" "What was the best thing you gained from...?" "Why was it the best gain?" and "How do you know that it was the best gain?"

Participating prospective teachers exhibited some sort of discomforts when they began working with those problems and demonstrated indicators of cognitive conflict. The nonthreatening conditions of the instructional environment and the guidance and support from the teacher during the discussions helped them resolve the conflicts. They realized that mathematical understanding is not immediate; rather, it is accompanied by several ups and downs. In this regard, one participating prospective teacher wrote: “... The historybased mathematics learning helped me become aware of the time that could be spent to solve some mathematical problems. ... I explored some [of the problems] and now I knew what I have to explore [more] in the future."

Well-designed discussions open the avenues for reflection and review of ideas. According to Bell (1993), exploring and resolving conflicts through discussion are in themselves reflective activities that promote the development of important schema for future use. It appears that this approach helped the majority of prospective teachers cue in favor of progressive items and against items that favor traditional beliefs in the theme time 
as evidenced in Table $2\left(t_{61}=2.57, p \leq 0.001\right)$ at the end of the intervention program. This was a significant achievement although some studies attain little change in this belief category after prospective teachers had participated in an intervention for a considerable time (e.g., Emenaker 1996).

Diverse applications of mathematics problems

In this case, participating prospective teachers were provided with mathematics problems that touch different aspects of mathematics, e.g., application of Fibonacci sequence to nature, art, algebra, geometry, application of the Pythagorean theorem to plane geometry, trigonometry, vectors, and spherical geometry. The prospective teachers found it unusual and frustrating to encounter problems that stretch that much. Some even forego or unduly shorten the act of hinting, inquiring, taking the first "answer" or solution that comes to them because of mental inactivity, frustration, and impatience, to get the conflict settled. It is here that the teacher intervenes to minimum guidance to create a nonthreatening environment.

Once the prospective teachers had gone through the methods of managing cognitive conflict, they settled the conflict and realized the richness and diverse application of mathematics. As inferred from their written and oral reflections, participants declared that they were modifying or abandoning several traditional beliefs related to the richness and diverse applications of mathematical concepts, ideas, constructs, principles, and problems. In this regard, the reflection of one prospective teacher called Abi goes:

... Consider the Fibonacci sequence, which is rich and applicable in many areas, relating mathematics and nature; and the Golden Ratio, which is applicable and [of] particular importance in the arts, and musical instruments... It is really everything; one can find it in several real-life situations. It really demonstrates the application of mathematics in nature and many other areas...

Changes in prospective teachers' beliefs toward progressive ones may be attributed to several aspects of the intervention. First, problems of the intervention trigger cognitive conflict. Then, the small-group and whole-class discussions after problem-solving and reflective writing activities helped the participants have the opportunity to argue and reflect on one another's ideas, and communicate with the solution processes of the problems. It seems worthy to conclude that the items of the problem set challenged prospective teachers to realize that mathematics and mathematics problems can be made rich to enhance learning, and thus lined in support of items that demonstrate progressive beliefs and not in favor of those that cue on traditional beliefs. In this case, quantitative data in Table 2 $\left(t_{61}=1.90, p \leq 0.05\right)$ ally with the qualitative analysis. There is nothing new with this proposition; Davis (1996) argues that context-rich problems are strongholds for changing views which lead to mathematical achievement and performance. For Bell (1993) as well, problems with such features were found helpful in transferring a given structure to a new context of learning.

Multiple solution strategies

Several participating prospective teachers admitted that they were constrained with the belief that for every problem of mathematics, there is one unique approach leading to its 
solution. Many of them were observed laboring to study precisely and recall entire proofs of mathematical theorems and problems. Hence, the participants were bemused and, in doing so, underwent signs of cognitive conflict, as they were shown with multiple strategies how to tackle mathematical theorems and problems, e.g., the Euclid's elegant method, the Chinese method, Abraham Garfield's method, and the common textbook proof to the Pythagorean theorem. Small-group and whole-class discussions following problemsolving activities revealed that many of the prospective teachers would never have thought to look for a different approach to a mathematics problem.

Participants, who used to try multiple approaches, stated that the intervention has helped them build confidence on their personal experience. In line with the quantitative study that indicates significant shifts $\left(t_{61}=1.97, p \leq 0.05\right)$ (Table 2$)$, participants declared that they were correcting their debilitating belief of one-solution-for-one problem by the empowering approach of multiple-solutions-for-one problem. Further, engaging prospective teachers in solving problems of the type helped them acquire ways of thinking, habits of persistence, and curiosity, and confidence in unfamiliar situations. After solution methods were public, students were asked to (a) check whether all the solution strategies are valid, (b) compare for superiority of one solution method over the other, and (c) reflect on what they learn from the scenario. Problems of this type have the power of integrating multiple topics, involving significant mathematics, calling for problem-solving, integrating mathematical problems with other contexts, encouraging a variety of problem-solving strategies, and offering the opportunity to monitor and reflect on the process of problem-solving NCTM (2000).

\section{Discovery in mathematics}

Mathematics is rarely perceived as a subject where average people can discover concepts, formulas, and generalizations in their own way. One of the purposes of the intervention was to show participating prospective teachers that this is not the case. Hence, they were exposed to an anomalous situation-they were required to use "the constant difference method" or "Polya's problem-solving strategies" to determine the 30th triangular number and generalize it for the $n$th triangular number, and then to develop formulas for the remaining figurate numbers. The moment the prospective teachers were introduced to the problems, most of them were not sure on the appropriateness of requiring them to develop or devise a formula, as exhibited in their questions, such as "How could we do this?" "Isn't it really challenging [for us] to derive a formula?" "Shouldn't we leave driving formulas to geniuses? Analyses of teachers' writing reflections and class discussions revealed that they were able to move from the traditional beliefs of "leave-mathematics-togeniuses" toward progressive belief of "we-can-discover-mathematical relationships." One participating teacher by the name of Tkuab wrote: "I had to discover and figure everything out on my own way, instead of waiting for someone to do or explain for me. I had to figure it out for my own which I had never attempted earlier." As indicated in the quantitative study displayed in Table $2\left(t_{61}=1.90, p \leq 0.05\right)$, participating prospective teachers changed their beliefs toward a more progressive one that they can discover mathematical ideas on their own endeavor.

Incidentally, Cangelosi (1996) as well as Freundenthal (1971) argues that when students are engaged in discover-a-relationship and construct-a-concept activities, they develop the view that mathematics is discoverable and develop the confidence that they can discover mathematical relationships at their own endeavor. 
Gender equity in mathematics

A considerable number of prospective teachers believe that female students need to exert extra effort in mathematics to perform as well as their male classmates. Hence, many of them harbor the belief that females make minimum contributions in the development of mathematics and discovery of mathematical formulas. This is congruent with the wellknown myth depicting mathematics as "a male discipline" (Ginsburg and Baron 1993). It has to be noted that this myth has profoundly grave implications on teachers' classroom practice. As correcting this belief has profound consequences, participating teachers were challenged by being exposed to explore the "witch of Agnesi" or "curve of Agnesi" and the pretty properties of the curve. They were, also, asked to explore the works of female mathematicians and the cultural influence on female mathematicians since ancient times. The impact of the intervention, in this case too, was positive, as indicated in quantitative study where mean score difference of "equity," stood at $\left(t_{61}=1.93, p \leq 0.05\right.$ : Table 2$)$. It appeared then the analyses of prospective teachers responses to the items in the questionnaire indicated that there is a significant shift from the traditional belief that "mathematics is a male-domain" toward the progressive belief that "mathematics is domainneutral." Study of the participants' written reflections and oral presentations during group and whole-class discussions demonstrated shifts toward progressive beliefs. A female participant by the name of Tafesu wrote the following:

The history-based mathematics program truly opens the opportunity for me to revisit history and thereby assess female mathematicians' contributions to the development of the discipline. Females' involvement in mathematics has begun [since] the time of ancient Greeks, Hypotia being the distinguished commentator of the time. Many well-known female mathematicians followed her in later times and contributed their shares to the advancement of mathematics. Hence, the program helped me revise my old thoughts and beliefs about the roles and contributions of females in the discovery of mathematical ideas.

This reflection lends support from Kenschaft (2005), who reported that success stories on females' mathematical achievement and changing views were evident when history is used as means to attain these goals.

\section{Memorizations versus understanding of mathematics}

Participants of this study began with a strong belief that mathematics can be learned and understood through memorization of facts and formulas. This is in line with the belief that there is only one correct way to solve problems of mathematics. When the prospective teachers were required to work on the Fibonacci sequence-where no single rule or formula is better over the other, they were visibly uncomfortable and frustrated. They realized as the result of the intervention, though, that memorization is inadequate in mathematics. They further declared that learning with understanding is retainable for, retrievable for, considerable in and addable to enhance future learning. The significant shift in belief systems toward progressive ones on the themes memorization and understanding, as revealed in the quantitative study, displayed in Table $2\left(t_{61}=2.16, p \leq 0.01\right)$ and $\left(t_{61}=2.15, p \leq 0.05\right)$, respectively, indicated that the intervention was effective in changing participants' views toward an enhanced position. Similar conclusions can also be inferred from the written reflections and oral presentations of the prospective teachers. A female prospective teacher, named Sara commented that: 
Before I enrolled to this [history-based] program, I used to study mathematics through memorization of formulas, procedures, algorithms, and rules. The historybased [program] was different ... the problems are not formula-guided. They challenged me [to] drive my own solution methods and reach at the formula. ... Once [I] achieved through this route, they [lessons] are long lasting; no need to memorize the formula because I can drive it again. I found memorization less important ... understanding superior.

The reflective comments such as "memorization is less important... understanding is superior" and the analyses of the prospective teachers' responses to the items in the questionnaire indicated that memorization and understanding of concepts appeared to be at "opposite ends of the continuum," emphasis toward understanding of basic concepts and away from memorization of basic concepts. This has something in common with Bell's (1993, p. 9) idea of mathematical connectedness that "a fundamental fact about learned material is that richly connected bodies of knowledge are well retained; isolated elements learned through memorization are quickly lost."

\section{Knowing versus step}

To fix the traditional beliefs related to knowing mathematics, the intervention included activities from the Konigsberg's Bridges problem and Euler's solution method to the problem. The intervention emphasized the teaching of "doing mathematics" and "what is doing mathematics" instead of teaching the step-by-step procedure in the processes of solving mathematical problems. Hence, participating prospective teachers were asked to decide whether "knowing or attending to the step-by-step procedure" guarantees understanding of the Bridges problem. For this purpose, they were required to solve the problem using their own way. However, they were neither capable nor comfortable to attend the activities. Similarly, the participants were hesitant, uncertain, and troubled to accept Euler's solution to the Bridges problem-where the shores were represented as points (nodes) and the bridges were represented as lines (arcs). An experience that involves some of the same conditions was a priority to help them resolve the conflict reflectively.

Examination of written reflections and notes of oral presentations and whole-class discussions revealed that the participants were holding a good number of traditional beliefs related to knowing in mathematics. Toward the completion of the intervention, fortunately, the participants demonstrated significant shifts toward progressive beliefs. In this regard, one participating teacher named Alem stated that:

I was impressed [by] Euler's solution process to the Konigsberg's Bridges problem. ... It was really out of the sphere of my imagination to represent the "islands" and the "shores" as "points" (nodes or vertices) and the "bridges" as "arcs" ("lines") without loss of generality. Now, I am highly satisfied and convinced with Euler's approach to the problem. In fact, this initiated me to see solutions to problems from different perspectives. The thoughtful reflection and arguments with colleagues and the teacher helped me understand how much mathematical problems demand perseverance and keen attention.

The impact of strong reflection on change of beliefs as was the case by many participants is demonstrated in the quantitative study depicted in Table 2 (Knowing mathematics- $t_{61}=2.62 ; p \leq 0.01$; and step- $\left.t_{61}=2.75 ; p \leq 0.001\right)$. In other words, analyses of the responses of prospective teachers' on the themes knowing and step indicated that they 
placed these two themes on opposite positions that favor knowing which involves mathematical knowledge which is holistic, unified, coherent, and interrelated, instead of preaching step-by-step procedures and algorithms entailing separate bits and pieces of information. The results suggest that the intervention helped participants realize that knowing mathematics is a broad concept, far beyond "getting the right answers quickly," "retrieving information quickly," and "figuring out formulas and equations to solve problems immediately." Similarly, significant improvement in issues related to solution steps in mathematics implies that the intervention assisted the prospective teachers to realize that many mathematics problems can be solved without having to rely on the memorized step-by-step procedures. One participant teacher by the name of Lucy wrote that:

I [realized that] knowing mathematics [...] is more than holding a step-by-step procedure. I believe that knowing mathematics helps [one work] on mathematics at large;.i.e., discover new ideas, give them meaning personally. I learn from this course that knowing the mathematics guarantees discovering the step-by-step procedure in a meaningful way. I found the step-by-step procedure is a small component of ... knowing mathematics.

If knowing mathematics is a means to able to do the mathematics, the history-based intervention program helped the prospective mathematics teachers' favor knowing mathematics by diminishing the role of holding a step-by-step procedure and rote memorization in solving mathematics problems. Knowing the mathematics has a correspondence with enabling students to construct their own knowledge by means of "doing" mathematics, solving problems, and organizing the subject matter (Dossey 1992; Freundenthal 1971; Polya 1988).

Was the intervention served equally well for all prospective teachers?

Quite a few of the participating prospective teachers who were involved in the study demonstrated little interest and appreciation for the history-based intervention which involved problem-solving and reflective writing activities. These participants illustrated weakened interest in writing and did not believe that reflective writing in mathematics conceded any form of self-monitoring nor did it encourage the integration of mathematical concepts. They provided narrow descriptions of the items for the reflective writing in the affective set. By and large, their reflective comments were reasonably short-lived. This weakness in reflective writing in part may occur because the learning preference of these prospective teachers does not match the approach employed in the intervention, or they feel that the intervention has no contribution to course grading. They seem to fail to see the intervention as an opportunity to improve their understanding and thereby shift traditional beliefs to more progressive beliefs about the nature, teaching, and learning of mathematics as demonstrated in the following four student excerpts.

Rakib stated,

I feel writing will uplift in my ability to reflect about leaned mathematical ideas. But I do not think it will add much understanding to these complex problems. It had better to have readymade formulas because it will save time to do much of other mathematical ideas. 
Tikun wrote,

I discovered that writing about learned mathematical ideas is to demonstrate the level of understanding in other ways. I get the writing part frustrating; I have difficulty organizing them in a sense making way. I believe that this is time wasting; I rather prefer attending the formulas and solve problems using these formulas.

Weina commented,

In my view, mathematics needs calculation not writing. Writing not was part of my evaluation in mathematics tests and examinations ever before. Why I write for it will not contribute to examination and understanding.

Marie remarked,

Writing and math may be intertwined, but I did not see its relevance. I developed feeling of distaste about this writing; may I improve it in the future?

\section{Limitation of the study}

This study has some limitations. One issue is the teacher-as-researcher may incorporate some bias by guiding the participants to magnify progressive beliefs-the study's purpose. It is believed that it would be too much of a challenge to control any carryover effect due to the teacher-as-researcher beliefs about the nature, teaching, and learning of mathematics. However, specific ethical measures were introduced to respect the integrity and individuality of the participants. Participants were strictly advised to reflect their feelings freely and honestly as informed consents.

Another limitation is with regard to the research design. The absence of control or comparison group in the one-group pretest-posttest design could compromise the internal validity. Thus, it can be argued that no one can confidently say that the change between the pretest and posttest is brought by the intervention only. However, every attempt was made to minimize the threat to validity at the designing, data collection, and data analyses stages of the interventions. Besides, the study was complemented using qualitative data in the form of participating teachers' written reflections and whole-class discussions. Another critical limitation of this study concerns the small sample size of participants. This made it difficult to offer more detailed quantitative evidence for the research questions posed and thus made it difficult to draw strong conclusions and generalizations.

An additional concern of this study was that only one institution was used in the study. Inclusion of more number of institutions could have provided a larger sample, but may have also introduced changeability between learning environments and across instructors for the intervention sections.

The fourth limitation is related to the method of data analysis for qualitative aspect-the reflective writing. We felt that the method of data analysis used is not sufficiently rigorous to document results in a coherent whole. We realized that "template analysis" or "thematic coding" was more appropriate as it involves a lot of coding (a template), representing themes in their textual data which came through a process of several modifications. 


\section{Contributions and implications for practice}

In accommodating the potential role of the history of mathematics in shifting traditional beliefs to progressive beliefs, one of the first requirements for teacher educations is that their training programs must be flexible enough to nurture courses that involve the historical background of basic mathematical topics. To put this into effect, it is strongly recommended that prospective teacher training programs should include, as Katz (2000) and Mac an Bhaird (2009) have indicated, a wide variety of context-rich problems from the history of mathematics that are appropriate for (1) problem-solving and (2) reflective writing, in ways that trigger cognitive conflict. In his analysis of the role of incorporating the historical development of mathematical topics in the teaching and learning of mathematics, Katz (2000) found that some of the difficulties prospective teachers encountered in understanding basic mathematical ideas and the development of negative attitude toward the subject are very much attributed to their lack of exposure to context-rich problems that challenge their thinking. Also, as a result of lack of exposure to the historical developments of mathematical contents, most of the prospective teachers fail to detect their "intellectual needs" in the learning of mathematics. Recently, prospective teachers are not engaged in problem-solving and writing activities that initiate cognitive conflict in their learning of mathematics. As a result, these prospective teachers' harvest traditional beliefs that impede their learning of mathematics. The inclusion of the basic historical developments of and context-rich mathematical topics in the training programs of teacher educations not only enable prospective teachers discover relationships and construct concepts but help them develop problem-solving strategies and reflective thinking skills. These context-rich problems, in turn, create anomalous conditions, the resolution of which would be considered as mainstays in shifting traditional beliefs to progressive ones. Also, prospective teachers' interest to wrestle with complex problems and to conjecture mathematical statements appeared to be heightened when they are engaged in such learning conditions.

Careful and minimal teacher interventions, whereby working as a guide, co-learner, and one, who facilitates engagement in the activities, encouraged prospective teachers to stretch their existing knowledge and extend their conceptual network of facts, relationships, and their implications to the teaching and learning of mathematics. This lends support from Bell (1994), who argued diagnostic conflict discussion along with feedback from the teacher will have long-term retention as compared with the conventional approach which results in poor retention of a learned material. Engaging prospective teachers in reflection and discussion sessions encouraged them to express their perceptions of the situation in as many different ways as possible, thereby able to connect the new knowledge firmly with the old. In this regard, prospective teachers' engagement with the material was much higher with those questions that caused cognitive conflict, and they worked harder and thought more on the questions that intrigued them. This perspective is in line with Bell's (1993), who suggested ensuring connectedness, structural transfer across context, feedback, reflection and review, and intensity as successful elements of resolving conflict during the process of discussion.

Finally, this research allies with Thompson's (1992) major areas of mathematics education to which research on teachers' beliefs has made important contributions, which include the following: (1) mathematics teacher education and research on teacher education, and (2) research on mathematics teaching and learning. In regard to this, we believe that this study made three specific contributions. First, we think the system we designed to assess a prospective teacher's change of beliefs has contributed an effective instrument for mathematics teachers and researchers to use in testing for change of beliefs. Second, we 
feel the design of the history-based intervention provides a helpful instrument to mathematics teachers and researchers. And finally, the contribution can be featured as a successful research implementing history-based intervention similar to other research projects that report success stories (e.g., Carpenter et al. 1989; Silver et al. 1995).

\section{Conclusions}

Quantitative and qualitative analyses of this intervention suggest several conclusions. The first conclusion is that a history-based intervention involving problem-solving and reflective writing activities does have a desirable impact in shifting prospective teachers' beliefs to progressive beliefs that promote student learning of mathematics. This research finding is consistent with the reports of Furinghetti (2000), Katz (2000), and Mac an Bhaird (2009) who reported that college learners subjected to the historical developments of mathematical ideas and problem-solving activities showed improved views toward and attainment in mathematics. It also obtained support from Emenaker (1996) and Hart (2002) who suggested problem-solving and method/content integrated courses, respectively, to challenge prospective teachers' beliefs.

The second conclusion is to identify the components of the history-based intervention in challenging traditional beliefs and boosting the development of progressive beliefs among the participants. This study evidenced that a history-based intervention that involves problem-solving and reflective writing activities that trigger cognitive conflict as a teaching approach challenged prospective teachers' existing conceptions about mathematics and the learning and the teaching of mathematics. While Fraser (2007), Schoenfeld (1992), as well as NCTM (2000) affirm problem-solving activities to improve views toward mathematics, and the teaching and learning of mathematics, Idris (2009) and NCTM (2000) assert reflective writing as a key to improve metacognitive skills and, thus, perceptions toward mathematics. To support the role of context-rich problems, Bell (1993, p. 17) argues that “... repeated memorization tasks may produce short-lived results; intensive insightdemanding tasks produce longer-term gains."

The third conclusion is our observations during the interventions that led us to conclude that the problem-solving and reflective writing activities as extracted from history stimulated cognitive conflict help prospective teachers to identify their "intellectual gap." The findings that both use of the cognitive conflict in a nonthreatening way and recognizing the multidimensional perspectives that affect the cognitive conflict as a teaching mechanism is important in challenging the mathematical beliefs of prospective teachers'. Similar observations were also made by Hadas et al. (2000); Zaslavsky (2005); Lee et al. (2003); Fraser (2007); and Stylianides and Stylianides (2008).

Open Access This article is distributed under the terms of the Creative Commons Attribution License which permits any use, distribution, and reproduction in any medium, provided the original author(s) and the source are credited.

\section{Appendix 1}

See Table 3. 


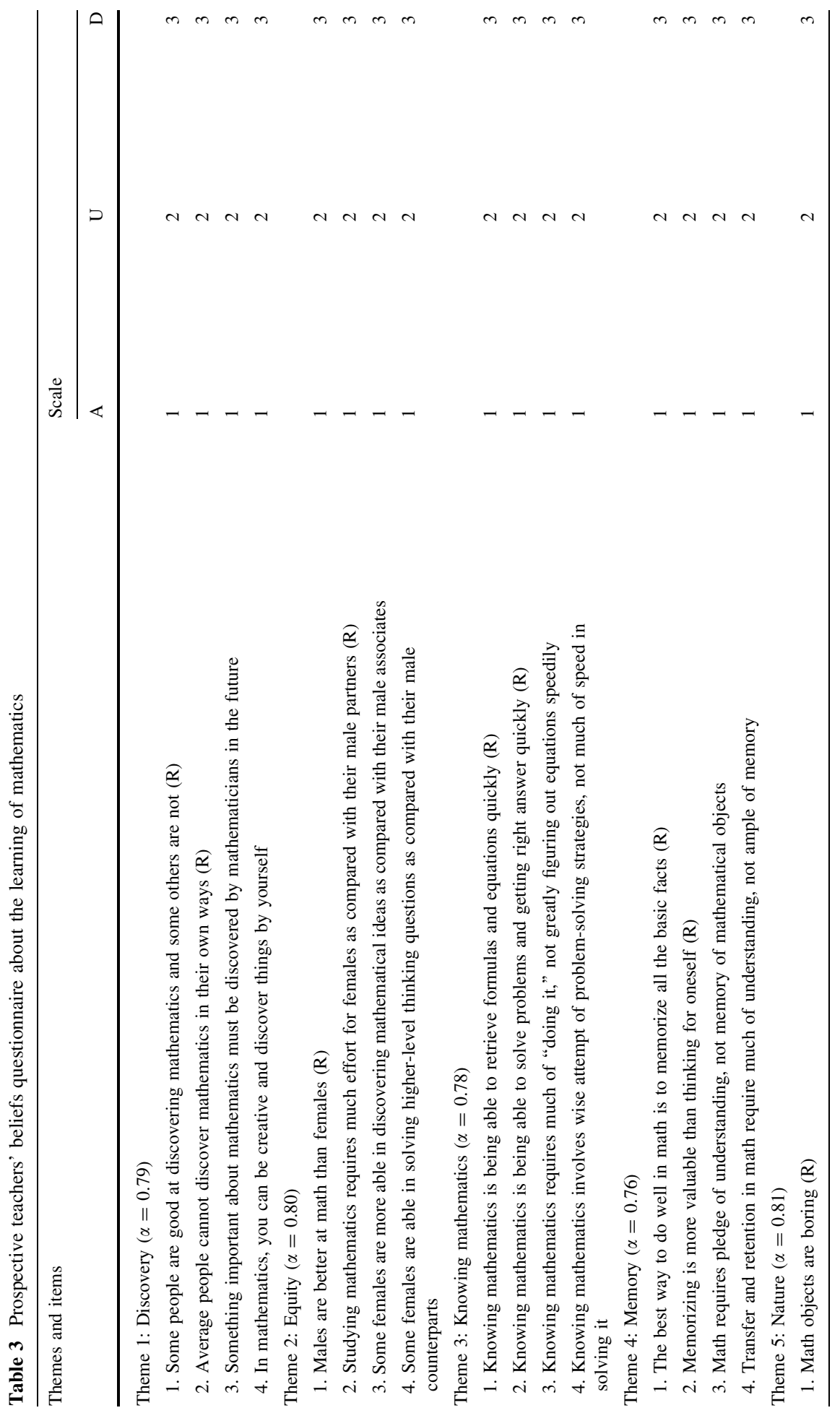




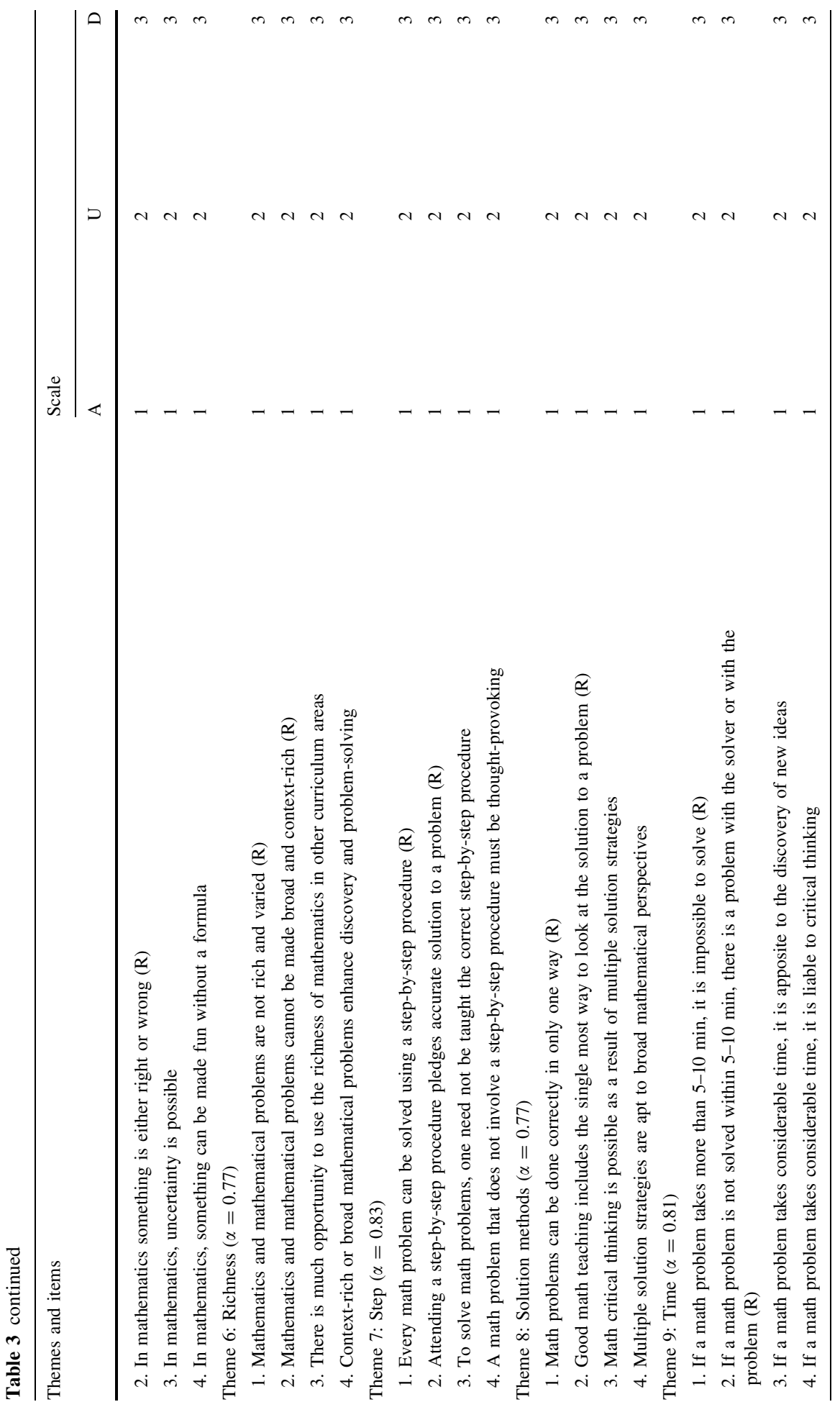




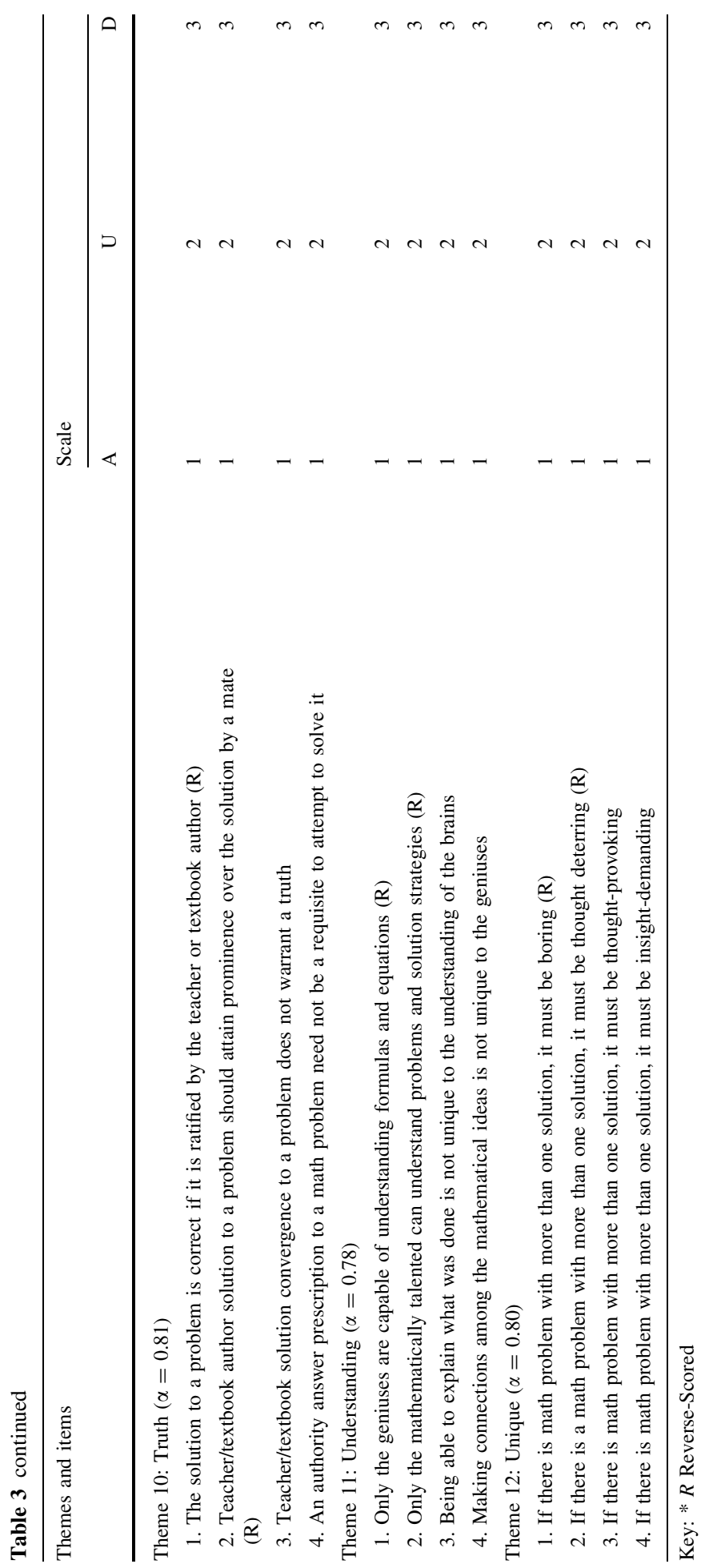




\title{
Appendix 2
}

\author{
See Table 4.
}

Table 4 Mathematical set

Problem 1: The three famous problems of antiquity

(a) Discuss in detail the three famous problems of antiquity

Duplication of the cube

Trisection of an angle

Quadrature of the circle

(b) Discuss the outcomes of these problems and the contributions made as result of the attempts to solve these problems

Problem 2: Pythagorean numbers

(a) Describe the Pythagorean numbers completely (figurate, deficient, abundant, amicable/friendly)

(b) Use problem-solving strategies or the method of constant difference to derive the $n$th term formula for some figurate numbers

(c) What does this mean to algebra and geometry?

Problem 3: Pythagorean theorem

(a) Present at least three proof methods of the Pythagorean theorem (Euclidean, Chinese, Abraham Garfield, etc.)

(b) Describe how Pythagorean theorem and the law of cosines are similar or different

(c) Visit the nature of the theorem in different axiomatic systems (Euclidean, coordinate system, vector space, spherical geometry)

(d) Generalize the Pythagorean Theorem for plane geometry

Problem 4: Fibonacci sequence

(a) Describe the Fibonacci sequence in detail

(b) Use different axiomatic systems to describe the Fibonacci sequence (recurrence relations, determinants, sequence in calculus)

(c) Describe the diverse nature of the Fibonacci sequence and explore relationships in each of the following

Fibonacci and nature

Fibonacci and art

Fibonacci and algebra

Fibonacci and geometry

Problem 5: Fermat's last theorem

(a) Describe Pierre De Fermat's last theorem completely and verify it up to $n=10$

(b) How are Fermat's last theorem and the Pythagorean theorem the same or different?

(c) Discuss the contributions of Fermat's last theorem to the development of mathematics

Problem 6: Conjectures

(a) Discuss the following conjectures and verify them to a considerable level

The twine prime conjecture

Goldbach conjecture

The odd perfect number conjecture

The Ulam's (The " $3 x+1$ " conjecture)

(c) Explore some important relationships, for example, what does the " $3 x+1$ " mean?

(b) Discuss the contributions of these conjectures to the development of mathematics

Problem 7: Konigsberg Bridges Problem

(a) Describe terminologies used in Euler's solution to Konigsberg Bridges Problem

(b) Analyze Euler's solution to Konigsberg Bridges Problem

(c) Use matrix notation to describe and discuss the topological distance among the nodes of the network developed by Euler

Problem 8: The four color conjecture/theorem

(a) In your own words, describe completely the four color conjecture by giving your own examples

(b) Introduce a region which is one colorable

(c) Introduce a region which is two colorable, three colorable. Is that enough to have only three colors to shade any number of regions where any two regions having common boundaries will not have the same color?

(d) Find a free map of your region. Use two colors to shade the administrative divisions. Was it possible to shade with a different color for every administrative division having a common boundary? What about with three colors? Four colors? Use a free map of Africa which is divided into distinct countries. How many colors are needed to shade completely where any two countries having a common boundary will not have the same color?

(e) Suppose you have not had colors at hand. What alternative can be employed in place of the colors? 
Table 4 continued

Problem 9: Crisis in the history of mathematics and the philosophy of mathematics

(a) Write a short note on the crisis in the history of mathematics

(b) Discuss the major philosophies of mathematics

(c) What was the role of the philosophies of mathematics in resolving the crises?

(d) Cite individual contributions in settling the crisis in the history of mathematics

\section{Appendix 3}

See Table 5.

Table 5 Affective set

Problem set- $(1,2,3, \ldots, 9)$. Put a number on blank to indicate problem set

1. What do you learn from this famous problem and its nature in this week? Discuss (in paragraph form) the skills and knowledge you have developed from this famous problem and its nature. What was the best thing you gain from this problem? Why was this the best gain? How do you know that it was the best gain?

2. Give a key moment when your understanding in and perception toward mathematics have changed. How do you know that your understanding and perception were changed? Do you feel the problem has been changed your feeling toward the nature of mathematics and mathematical problems? How do you know that?

3. Imagine your perceptions about the learning, teaching, and nature of mathematics just before your enrollment to this program and after the intervention. Describe how you would have observed the change on yourself

4. Discuss whether or not the problem-solving activities promote meaningful learning in mathematics and if contributed to enhance perceptions on the learning, teaching as well as on the nature of mathematics. Do you think working on this problem-solving activity was helpful and relevant for your professional career and to the courses you are learning? Explain how!

5. Which were the most difficult parts of this problem? Why were difficult for you? How relevant did you find the ideas of this problem?

6. How has this problem-solving activity helped (or hindered) your motivation to learn more about mathematics and thereby change your views toward the learning, teaching, and nature of mathematics? Has it encouraged you, or discouraged you? How has your learning on this task affected your practices?

7. List down a number of female mathematicians from the history of mathematics. Write a piece in favor of one female mathematician that you appreciated most. You are expected to reason out why you have appreciated most

8. What was the least work for you? What did you learn from this? How could you overcome the concern?

\section{References}

Adey, P., \& Shayer, M. (1993). An exploration of long-term far-transfer effects following an extended intervention program in the high school science curriculum. Cognition and Instruction, 11(1), 1-29.

Bell, A. (1993). Principles for the design of teaching. Educational Studies in Mathematics, 24, 5-34.

Bell, A. (1994). Teaching for the test. In S. Selinger (Ed.), Teaching Mathematics (pp. 41-46). London: The Open University in association with Routledge.

Benbow, R. M. (1993). Tracing mathematical beliefs of prospective teachers through integrated content method courses. In Proceedings of annual conference of the American educational research association. ERIC Document Reproduction Service No. ED 388638.

Berlyne, D. E. (1965). Curiosity and education. In J. Krumboltz (Ed.), Learning and the educational process. Chicago: Rand-McNally.

Beswick, K. (2007). Influencing teachers' beliefs about teaching mathematics for numeracy to students with mathematics learning difficulties. Mathematics teacher Education and Development, 9, 3-20. 
Biggs, J. (1990). Teaching for desired learning outcomes. In N. Entwistle (Ed.), Handbook of educational ideas and practices (pp. 681-693). New York: Routledge.

Boaler, J. (1997). Experiencing school mathematics: Teaching styles, sex, and setting. Buckingham: Open University Press.

Boyer, C. (1991). A history of mathematics (2nd ed.). New York: Wiley.

Bruner, J. (1966). Toward a theory of instruction. New York: W.W.Norton and Company Inc.

Cangelosi, J. S. (1996). Teaching mathematics in secondary and middle school: An interactive approach (2nd ed.). New Jersey: Prentice Hall.

Carpenter, T., Fennema, E., Peterson, P., Chiang, C., \& Loef, M. (1989). Using knowledge of children's mathematical thinking in classroom teaching: An experimental study. American Educational Research Journal, 26, 499-532.

Civil, M. (1990). A look at four prospective teachers' views about mathematics. For the learning of mathematics, $10(1), 1-40$.

Clark, C. M., \& Peterson, P. L. (1986). Teachers' thought processes. In M. C. Wittrock (Ed.), Handbook of research on teaching (pp. 255-296). New York: Macmillan.

Cobb, P., Wood, T., \& Yackel, E. (1990). Classrooms as learning environments for teachers and researchers. In R. Davis, C. Maher, \& N. Noddings (Eds.), Constructivist views on the learning and teaching of mathematics. Journal for Research in Mathematics Education Monograph (pp. 125-146). Reston, VA: National Council of Teachers of Mathematics.

Cohen, L., Manion, L., \& Morrison, K. (2000). Research methods in education. London: Rutledge Falmer.

Collier, C. P. (1972). Prospective elementary teachers' intensity and ambivalence of beliefs about mathematics and mathematics instruction. Journal for Research in Mathematics Education, 3, 155-163.

Davis, R. B. (1996). Cognition, mathematics, and education. In L. P. Steffe \& P. Nesher (Eds.), Theories of mathematics learning (pp. 285-299). Mahwaw, NJ: Erlbau.

Dewey, J. (1933). How we think: A restatement of the relation of reflective thinking to the educative process. Lexington, MA: D.C.Heath.

Dossey, J. A. (1992). The Nature of Mathematics: Its Role and Its Influence. In D. A. Grouws (Ed.), Handbook for research in mathematics education (pp. 39-64). New York: Macmillan.

Dreyfus, A., Jungwirth, E., \& Eliovitch, R. (1990). Applying the "cognitive conflict'" strategy for conceptual change: Some implications, difficulties, and problems. Science Education, 74, 555-569.

Druyan, S. (1997). Effect of the kinesthetic conflict on promoting scientific reasoning. Journal of Research in Science Teaching, 34, 1083-1099.

Elizabeth, L. L., \& Galloway, D. (1996). Conceptual links between cognitive acceleration through science education and motivational style: A critique of Adey and Shayer. International Journal of Science Education, 18, 35-49.

Emenaker, C. (1996). A problem-solving mathematics course and elementary teachers' beliefs. School Science and Mathematics, 96(2), 75-84.

Ernest, P. (1989). Mathematics teacher education and quality. Assessment and Evaluation in Higher Education, 16(1), 56-65.

Eves, H. J. (1990). An introduction to the history of mathematics with cultural connections. Philadelphia: Saunders College Publishing.

Festinger, L. (1957). A theory of cognitive dissonance. Stanford, CA: Stanford University Press.

Fleener, M. J. (1996). Scientfic and world building on the edge of Chaos: High school students' beliefs about mathematics and science. School science and mathematics, 96, 312-320.

Foss, D. H., \& Kleinsasser, R. C. (1996). Preservice elementary teachers' views of pedagogical and mathematical content knowledge. Teaching and Teacher Education, 12(4), 429-442.

Frank, M. L. (1990). What myths about mathematics are held and conveyed by teachers? The Arithmetic Teacher, 37(5), 10-12.

Fraser, D. (2007). Using cognitive conflict to promote a structural understanding of grade 11 algebra. Unpublished master's Thesis. Simon Frazer University.

Freundenthal, H. (1971). Geometry between the devil and the deep sea. Educational Studies in Mathematics, $3,413-435$.

Furinghetti, F. (2000). The History of mathematics as a coupling link between secondary and university teaching. International Journal of Mathematical Education in Science and Technology, 31(1), 43-51.

Gerland, T. H. (1987). Facinating fibonaccis: Mystery and magic in numbers. USA: Dale Seymour Publications.

Ginsburg, H. P., \& Baron, J. (1993). Cognition: Young children's construction of mathematics. In R. J. Jensen (Ed.), Research ideas for the classroom: Early childhood mathematics (pp. 3-21). New York: MacMillan.

Goulding, M. (2004). Learning to teach mathematics in secondary school. London: David Fulton Pub. Ltd. 
Green, T. F. (1971). The activities of teaching. New York: McGraw-Hill.

Hadas, N., Hershkowitz, R., \& Schwarz, B. (2000). The role of contradiction and uncertainty in promoting the need to prove in dynamic geometry environments. Educational Studies in Mathematics, 44, 127-150.

Haley-James, S. (1982). Helping students learn through writing. Language Arts, 59(7), 726-731.

Handal, B. (2003). Teachers' mathematical beliefs: a review. The Mathematics Educator, 13(2), 47-57.

Hart, L. C. (2002). Pre-service teachers' beliefs and practices after participating in an integrated content/ method course. School Science and Mathematics, 102(1), 4-14.

Hewson, P. W., \& Hewson, M. G. (1984). The role of conceptual conflict in conceptual change and the design of science instruction. Instructional Science, 13, 1-13.

Hourigan, M., \& O'Donoghue, J. (2007). Mathematical under-preparedness: The influence of pre-tertiary mathematics experience on students' ability to make a successful transition to tertiary level mathematics courses in Ireland. International Journal in Mathematical Education in Science and Technology , 38(4), 461-476.

Hynd, C. (1998). Conceptual change in a high school physics class. In B. Guzzetti \& C. Hynd (Eds.), Perspectives on conceptual change (pp. 27-36). Mahwah, NJ: Erlbaum.

Idris, N. (2009). Enhancing students' understanding in calculus through writing. International Electronic Journal of Mathematics Education, 4(1), 36-55.

Johnson, D. W., \& Johnson, R. T. (1979). Conflict in the classroom: Controversy and learning. Review of Educational Research, 49, 51-70.

Katz, V. (2000). Using history to teach mathematics: An international perspective. Washington, DC: The Mathematical Association of America.

Keller, J. M. (1984). The use of the ARCS model of motivation in teacher training. In K. Shaw \& A. J. Trott (Eds.), Aspects of educational technology, vol. 17: Staff development and career updating. London: Kogan Page.

Kenschaft, P. C. (2005). Change is possible: Stories of women and minorities in mathematics. Providence, RI: American Mathematical Society.

Klyve, D., \& Stemkoski, L. (2009). The Euler archive. From http://math.dartmouth.edu/ euler/. Accessed 21 May 2012.

Knoebel, A., Laubenbacher, R., Lodder, J., \& Pengelley, D. (2007). Mathematical masterpieces: Further chronicles by the explorers. New York: Springer.

Kwon, J., Lee, Y., \& Beeth, E. (2001). The effects of cognitive conflict on students' conceptual change in Physics. Unpublished research report. ERIC Document reproduction service No. ED 443734.

Lampert, M. (1990). When the problem is the question and the solution is the answer: Mathematical knowing and teaching. American Research Journal, 27, 29-63.

Leatham, K. R. (2006). Viewing mathematics teachers' beliefs as sensible systems. Journal of Mathematics Teacher Education, 9, 91-102.

Lee, G., \& Kwon, J. (2001, January). What do you know about students' cognitive conflict: A theoretical model of cognitive conflict process. In Proceedings of 2001 AETS annual meeting, Costa Mesa, CA, (pp. 309-325). ERIC Document Reproduction Service No. ED 453083.

Lee, G., Kwon, J., Park, S., Kim, J., Kwon, H., \& Park, H. (2003). Development of an instrument for measuring cognitive conflict in secondary-level science classes. Journal of Research in Science Teaching, 40(6), 585-603.

Mac an Bhaird, C. (2009). Introducing the history of mathematics to third level students with weak mathematical backgrounds: A case study. From http://www.maths.nuim.ie/documents/MSOR/. Accessed 21 May 2010.

Madden, S. R. (2008). High school mathematics teachers' evolving understanding of comparing distributions. Unpublished PhD Dissertation. Western Michigan University: Kalamazoo, Michigan.

Maor, E. (2007). The Pythagorean theorem: A 4,000-year history. Princeton, NJ: Princeton University Press.

Masingila, J. O., Lester, F. K., \& Raymond, A. M. (2002). Mathematics for elementary teachers via problem solving: Student resource handbook. New Jersey: Upper Saddle.

McLeod, D. B. (1992). Research on affect in mathematics education: A Reconceptualization. In D. A. Grouws (Ed.), Handbook on research in mathematics education (pp. 575-596). New York: Macmillan Publishing Co.

Mischel, T. (1971). Piaget: Cognitive conflict and the motivation of thought. In T. Mischel (Ed.), Cognitive development and epistemology. New York: Academic Press.

Murphy, E. (1997). Characteristic of constructivist learning and teaching. Universite Laval, Quebec. Retrieved April 20, 2013, from http://www.stemnet.nf.ca/elmurphy/elmurphy/cle3.htlm.

National Council for Curriculum and Assessment [NCCA]. (2005). Review of mathematics in post-primary education. From http://www.ncca.ie/en/publications/consultativedocuments/. Accessed 16 Aug 2011. 
National Council of Teachers of Mathematics. (2000). Principles and standards for school mathematics. Reston, VA: Author.

Niaz, M. (1995). Cognitive conflict as a teaching strategy in solving chemistry problems: A dialecticconstructivist perspective. Journal of Research in Science Teaching, 32, 959-970.

Nisbert, S., \& Warren, E. (2000). Primary teachers' beliefs relating to mathematics teaching and assessing mathematics and factors that influence those beliefs. Mathematics Research Journal, 13(2), 34-47.

Piaget, J. (1985). The equilibration of cognitive structure: The central problem of intellectual development. Chicago, IL: University of Chicago Press.

Polya, G. (1988). How to solve it. Princeton, NJ: Princeton University Press.

Posner, G. J., Strike, K. A., Hewson, P. W., \& Gertzog, W. A. (1982). Accommodation of a scientific conception. Toward a theory of conceptual change. Science Education, 66, 211-227.

Renga, S., \& Dalla, L. (1993). Affect: A critical component of mathematical learning in early childhood. In R. J. Jensen (Ed.), Research ideas for the classroom: Early childhood mathematics (pp. 22-39). New York: Macmillan Publishing Co.

Rokeach, M. (1968). Beliefs, attitudes, and values. San Franscico: Jossey-Bass.

Rosen, K. H. (2006). Discrete mathematics and its applications. Boston: Mcgraw-Hill.

Schoenfeld, A. H. (1992). Learning to think mathematically: problem solving, metacognition, and sense making in mathematics. In D. A. Grouws (Ed.), Handbook on research in mathematics education (pp. 334-370). New York: Macmillan Publishing.

Schram, P., \& Wilcox, S. K. (1988, November). Changing prospective pre-service teachers' conception of mathematics teaching. In M. J. Behr, C. B. Lacampagne, \& M. M. Whealer (Eds.), PME NA, Proceedings of the tenth annual meeting (pp. 349-355). Dekalb, IL: Northern University.

Shirk, G. B. (1973). An examination of conceptual frameworks beginning mathematics teachers. Unpublished doctorial dissertation, University of Illinois at Urbana Champaign.

Silver, E. A., Smith, M. S., \& Nelson, B. S. (1995). The QUASAR project: Equity concerns meet mathematics education reform in the middle school. In W. G. Secada, E. Fennema, \& L. B. Adajian (Eds.), New directions for equity in mathematics education (pp. 9-56). New York: Cambridge University Press.

Simon, M. A., \& Schifter, D. (1993). Toward a constructivist perspective: The impact of a mathematics teacher inservice program on students. Educational Studies in Mathematics, 25, 331-340.

Sinatra, G. M., \& Dole, J. A. (1998). Case studies in conceptual change: A social psychological perspective. In B. Guzzetti \& C. Hynd (Eds.), Perspectives on conceptual change (pp. 39-53). Mahwah, NJ: Erlbaum.

Sobel, M. A., \& Maletsky, E. M. (1988). Teaching mathematics: A sourcebook of aids, activities, and strategies (2nd ed.). New Jersey, NJ: Prentice Hall.

Stevens, B. B. (2005). The development of pedagogical content knowledge of a mathematics teaching intern: The role of collaboration. Unpublished PhD Dissertation, University of Missouri-Columbia.

Strike, K. A., \& Posner, G. J. (1992). A revisionist theory of conceptual change. In R. A. Duschl \& R. J. Hamilton (Eds.), Philosophy of science, cognitive psychology, and educational theory and practice (pp. 147-176). Albany: State University of New York Press.

Stylianides, G. J., \& Stylianides, A. J. (2008). 'Cognitive Conflict' as a mechanism for supporting developmental progressions in students' knowledge about proof: Article for TSG-18, ICME-11 (2008).

Sundre, D., Barry, C., Gynnild, V., \& Ostgard, E. T. (2012). Motivation for achievement and attitudes toward mathematics instruction in a required calculus course at the Norwegian University of Science and Technology. Numeracy, 5(1), 1-20. doi:10.5038/1936-4660.5.1.4.

Thompson, A. G. (1991). The development of teachers' conceptions of mathematics teaching. In Proceedings of the 13th annual conference of the North American chapter of the international group for the psychology of mathematics education. ERIC Document Reproduction Service No. ED 352274.

Thompson, A. (1992). Teachers' beliefs: a Synthesis of the research. In D. A. Grouws (Ed.), Handbook on research in mathematics education (pp. 127-146). New York: Macmillan Publishing Co.

Tyson, L. M., Venville, G. J., Harrison, A. G., \& Treagust, D. F. (1997). A multidimensional framework for interpreting conceptual change events in the classroom. Science Education, 81, 387-404.

Vygotsky, L. S. (1978). Mind and society: The development of higher psychological processes. Cambridge, MA: Harvard University Press.

Wells, D. (1986). The penguin dictionary of curious and interesting numbers. England: Penguin Books. World Book Encyclopedia. (1994). World book international. London: A Scott Fetzer Company.

Zaslavsky, O. (2005). Seizing the opportunity to create uncertainty in learning mathematics. Educational Studies in Mathematics, 60, 297-321. 